\section{Leaf Cutin Monomers, Cuticular Waxes, and Blackspot Resistance in Rose}

\author{
S. Mark Goodwin, Christopher J. Edwards, and Matthew A. Jenks ${ }^{1}$ \\ Department of Horticulture and Landscape Architecture, Purdue University, \\ 625 Agriculture Mall Drive, West Lafayette, IN 47907
}

Karl V. Wood

Department of Chemistry, Purdue University, West Lafayette, IN 47907

Additional index words. Cuticular wax, cutin, blackspot disease, rose

\begin{abstract}
The fungal pathogen Diplocarpon rosae causes rose blackspot disease, a serious problem for roses $(R o s a)$ in the managed landscape. To prevent this disease, homeowners and professional growers often apply chemical fungicide. However, increased use of fungicides poses an environmental hazard and an economic burden to the user. New landscape rose cultivars like 'Knockout' possess increased disease resistance, but the biological basis for this resistance is still unknown. To investigate the potential role of leaf cuticle in blackspot resistance in rose, five rose cultivars known to vary greatly in blackspot resistance were examined for variation in the major lipids of the leaf cuticle, specifically the monomers of the cutin polyester and the free cuticular waxes. This is the first report of cutin monomers in the Rosa genera. The rose cultivars selected for this study were 'Knockout', 'Mister Lincoln', 'Garden Party', 'Purple Passion', and 'Bicolor'. 'Knockout' and 'Garden Party' had significantly lower total cutin monomer amount per leaf area than the other cultivars, whereas the most cutin monomers were observed on 'Purple Passion', 'Bicolor', and 'Mister Lincoln'. Five major cutin monomers (mostly hydroxylated 16 carbon fatty acids) dominated the cutin profiles of both adaxial and adaxial surfaces of all cultivars, with the 10,16-dihydroxy hexadecanoic acids being most abundant. The proportion of 10,16-dihydroxy hexadecanoic acids was slightly higher in the adaxial than abaxial leaf cuticles of all cultivars. Correspondingly, other cutin monomers were relatively lower in the adaxial cuticle, except 16-hydroxy hexadecanoic acid that differed little. Uniquely, this is the first report of cutin monomer composition of isolated abaxial and adaxial leaf cuticles of any plant. Total leaf cuticular wax amounts were lowest on 'Purple Passion' and 'Knockout', intermediate in 'Mister Lincoln' and 'Garden Party', and highest on 'Bicolor', with alkanes as the most abundant wax class. Consistent with previously published disease susceptibility ratings, our visual scores showed that 'Knockout' was most resistant to blackspot pathogen infection with a visual disease rating score of 1.0, followed by 'Mister Lincoln' at 1.8, 'Garden Party' at 5.4, 'Bicolor' at 7.5, and 'Purple Passion' with the most visible disease damage at 8.8. Regression analysis revealed that the alkane and ester proportions were most closely associated with blackspot disease susceptibility ratings, being inversely $\left(R^{2}=0.63, P=0.05\right)$ and directly $\left(\mathrm{R}^{2}=\mathbf{0 . 8 1}, P=0.05\right)$ correlated, respectively. More studies on the role of cuticle in rose susceptibility to blackspot are now clearly warranted.
\end{abstract}

Roses are among the most important ornamental plants, used both indoors as potted and cut flowers and in the outdoor managed landscape. As is well known, roses are susceptible to many kinds of environmental stress, including those incited by fungal pathogens, phytophagous insects, and drought. Among the most serious causes of rose foliar damage are fungal pathogens. The pathogen Podosphaera pannosa causes pow-

Received for publication 27 Mar. 2007. Accepted for publication 24 June 2007.

Publication number 2007-18233 of the Purdue University Office of Agricultural Research.

We thank The Fred C. Gloeckner Foundation for its support.

${ }^{1}$ To whom reprint requests should be addressed; e-mail jenksm@purdue.edu dery mildew and is especially problematic on roses grown in greenhouses (Braun and Takamatsu, 2000; Larson, 1992). Diplocarpon rosae causes blackspot disease and can be quite devastating to outdoor roses (Reddy et al., 1992). To control these problems, rose growers often turn to intense integrated pest management strategies, which often involve the application of chemical fungicides. However, the increased use of fungicides poses an economic burden to the user and contaminates natural ecosystems with toxic residues. Other problems with fungicide use include the development of pesticide resistance by the pathogens, toxicity to nontargeted beneficial organisms, difficulty in achieving proper plant coverage, and surfactant-induced damage to leaf surfaces that make plants vulnerable to attack by nontargeted pests. Recently, landscape roses with increased resistance to pathogens have been introduced, and this has reduced to some extent the need for certain pesticide applications. Notwithstanding, a better understanding of disease resistance mechanisms in rose could help in the development of new landscape management or rose breeding strategies that lead to further reduction in landscape application of pesticides. To date, however, the biological basis for this fungal pathogen resistance in rose is unknown.

Rose cultivars can vary significantly in their susceptibility to diseases incited by fungal pathogens (Castledine et al., 1981; Palmer et al., 1966; Reddy et al., 1992; von Malek and Debner, 1998; Xue and Davidson, 1998). Interestingly, Genders (1965) reported that glossy leaved varieties of rose were more troubled by the blackspot pathogen Diplocarpon rosae than the less glossy leaved varieties. Because the degree of glossiness or glaucousness of a leaf surface is the result of the amount of crystalline structure in cuticular wax deposits (Jenks and Ashworth, 1999), Genders' findings reveal that waxes of the rose cuticle may play an important role in rose pathogen resistance. Moreover, numerous studies in other plant systems show how diversity in the structure and composition of cuticular waxes can be associated with plant protection against fungal pathogens, sometimes in complex ways and often unique to the specific plant-pathogen interaction (Jenks and Ashworth, 1999). Recent studies also suggest that, besides waxes, the cutin component of the plant cuticle may also influence plant susceptibility to disease (Jenks et al., 1994; Xiao et al., 2004). To date, however, the exact function of either cutin or waxes in rose pathogen resistance is unclear. A detailed analysis of the cutin monomers and waxes of rose cuticle, along with an examination of disease resistance, in five important rose cultivars is reported here.

\section{Materials and Methods}

Plant material. Roses were grown in established research plots in the Purdue Horticultural Gardens, West Lafayette, IN. The rose cultivars examined were Rosahybrid 'Purple Passion', 'Garden Party', 'Mister Lincoln', 'Knockout', and Rosa foetida 'Bicolor' (syn. 'Austrian Copper'). These cultivars were chosen because previous published and nonpublished reports indicated that they would exhibit wide diversity in their susceptibility to the pathogen responsible for causing leaf blackspot disease. 'Bicolor' and 'Garden Party' were reported as highly susceptible, whereas 'Mister Lincoln" and 'Knockout' were reported as highly resistant (Holcomb and Raiford, 2001; Hong et al., 2001). For all cuticle lipid analysis, the central, terminal leaflets were excised from newly expanded leaves at the third node from the growing tip with a position as growing in full sun in early June 2004.

Leaf cutin monomer analysis. The cuticle membrane was enzymatically isolated from 
circular rose leaf disks of known area incubated at $37{ }^{\circ} \mathrm{C}$ in $20 \mathrm{~mm}$ citric acid adjusted to $\mathrm{pH} 3.7$ with $\mathrm{KOH}$ and $0.001 \%$ $(\mathrm{w} / \mathrm{v})$ phenylmercuric nitrate to prevent microbial growth. After $72 \mathrm{~h}$, the cuticle was separated from the bulk leaf material with fine forceps and placed in fresh enzymatic solution for an additional $48 \mathrm{~h}$ to completely remove any remaining cell wall material. Cuticle samples were then washed in an acetone series, transferred to chloroform:methanol (1:1) with $50 \mathrm{mg} \cdot \mathrm{L}^{-1}$ butylated hydroxytoluene, and refluxed in a Soxhlet apparatus for $24 \mathrm{~h}$. Cuticles were depolymerized using $14 \% \mathrm{BF}_{3}$ in anhydrous methanol to produce methyl esters that were extracted with diethyl ether as per Riederer and Schönherr (1986). Sample extracts were derivatized with [N, O-bis(trimethylsilyl)trifluoroacetamide] (BSTFA) and incubated for 30 min at $70{ }^{\circ} \mathrm{C}$. After surplus BSTFA was evaporated under nitrogen, the sample was redissolved in hexane for analysis with a Hewlett-Packard 5890 series II gas chromatograph (GC) equipped with a flame ionization detector. The $\mathrm{GC}$ was equipped with a $12 \mathrm{~m}, 0.2-\mathrm{mm}$ HP-1 capillary column with helium as the carrier gas. The GC was programmed with an initial temperature of $80^{\circ} \mathrm{C}$. The temperature was increased at $15^{\circ} \mathrm{C} / \mathrm{min}$ to $200{ }^{\circ} \mathrm{C}$ and then increased at $2{ }^{\circ} \mathrm{C} / \mathrm{min}$ to $280{ }^{\circ} \mathrm{C}$. Quantification was based on flame ionization detector peak areas and the internal standard eicosane added before depolymerization. Specific correction factors were developed from multilevel calibration curves (like for wax analysis; Jenks et al., 1995) developed from external standards hexadecanoic acid, hexadecane-1,16-dioic acid, 16-hydroxy hexadecanoic acid, and octadecanoic acid. All values shown in tables represent the average of four to six replicate samples. Selected subsamples were analyzed in a GCQ gas chromatograph-mass spectrometer (FinniganMAT/thermospray Corp., San Jose, CA). All cutins monomers were identified using the electron impact mass spectra of the methyl ester TMS derivatives on the basis of published spectra (Eglinton and Hunneman, 1968; Holloway, 1982), retention indices (Holloway, 1984), and retention times of the authentic standards.

Leaf cuticular wax analysis. The hexanesoluble cuticular waxes extracted from rose terminal leaflets of known area were evaporated to dryness and derivatized with BSTFA, like in Jenks et al. (1995). Samples were redissolved in hexane for analysis with a Hewlett-Packard 5890 series II GC equipped with a flame ionization detector. The GC was equipped with a $12 \mathrm{~m}, 0.2-\mathrm{mm}$ HP-1 capillary column with helium as the carrier gas. The GC was programmed with an initial temperature of $80^{\circ} \mathrm{C}$ and then the temperature was increased at $15{ }^{\circ} \mathrm{C} / \mathrm{min}$ to $260{ }^{\circ} \mathrm{C}$, where it remained unchanged for $10 \mathrm{~min}$. The temperature was then increased at $5{ }^{\circ} \mathrm{C} / \mathrm{min}$ to $320^{\circ} \mathrm{C}$ and then held for $15 \mathrm{~min}$. Quantification was based on flame ionization detector peak areas and the internal standard hexadecane. Specific correction factors were devel- oped from external standards and applied to the peak areas of the free fatty acids and alkanes. For all other peaks, a factor of 1.03 was assigned (the average correction for comparable standards and concentrations). As for cutin, mean total cuticular wax amount was expressed per leaf area representing four to six replicate plant samples. A GCQ gas chromatograph-mass spectrometer was used to verify peak identities as described previously.

Leaf blackspot disease susceptibility rating. Cultivars were scored visually, by three individual investigators, on a 0 to 10 scale with 0 representing a whole plant having no leaves that exhibited blackspot disease symptoms and 10 assigned to plants with $100 \%$ of leaves exhibiting at least some visible blackspot disease. All five cultivars displayed symptoms consistent with blackspot disease, including dark brown to black roughly circular leafspots up to one-half inch in diameter with irregular, feathery margins on the adaxial leaf surface (Xue and Davidson, 1998; Yokoya et al., 2000). Just as reported for previous rose blackspot studies (CarlsonNilsson and Davidson, 2006), rose disease susceptibility in this report was rated on the basis of percentage of leaves infected regard- less of the size of the spots. Scores represent the mean of three averaged ratings made by each of three investigators for each of four replicate plants within each cultivar recorded in mid-July 2004.

\section{Results}

Rose leaf cutin profiles. The total amount of cutin monomers varied among the five rose cultivars with the most cutin monomers being found on the rose cultivars 'Purple Passion', 'Bicolor', and 'Mister Lincoln' and the lowest on 'Garden Party' and 'Knockout' (Table 1). When individual adaxial and abaxial leaf cuticles were examined for each cultivar, they had total cutin monomer amounts on their adaxial and abaxial surfaces that were very similar (Table 1 ). The most abundant monomer on both adaxial and abaxial surfaces, the 10,16-dihydroxy hexadecanoic acids, were percentage-wise more abundant on the adaxial than abaxial surface, whereas correspondingly, the percentage of other monomers was generally slightly elevated in the abaxial cuticle, except 16-hydroxy hexadecanoic acids that differed little (Table 1). The cutin monomers 16-hydroxy hexadecanoic acids and 7-hydroxy hexadecane-1,16-dioic

Table 1. Cutin monomer amount $\left(\mu \mathrm{g} \cdot \mathrm{cm}^{-2} \pm \mathrm{SD}\right)$ and percent cutin monomers $(\% \pm \mathrm{SD})$ from enzymatically isolated adaxial and abaxial cuticles of leaves from the five selected rose cultivars. ${ }^{\mathrm{z}}$

\begin{tabular}{|c|c|c|c|c|c|c|}
\hline & $\begin{array}{c}16-\mathrm{OH} \mathrm{C} \\
\text { acid }\end{array}$ & $\begin{array}{c}\text { di-OH } \mathrm{C}_{16} \\
\text { acid }\end{array}$ & $\begin{array}{c}1,16 \\
\text { dioic acid }\end{array}$ & $\begin{array}{c}7-\mathrm{OH} \\
\text { dioic acid }\end{array}$ & $\begin{array}{c}10-\mathrm{OH} \mathrm{C} \\
\text { Acid }\end{array}$ & Totals \\
\hline \multicolumn{7}{|c|}{ Purple Passion } \\
\hline \multicolumn{7}{|l|}{ Adaxial } \\
\hline Amount & $2.2 \pm 0.6$ & $20.1 \pm 7.1$ & $0.1 \pm 0.0$ & $1.9 \pm 0.5$ & $0.8 \pm 0.2$ & \multirow[t]{2}{*}{$25.1 \pm 8.4$} \\
\hline Percent & $9.0 \pm 0.6$ & $79.8 \pm 1.3$ & $0.5 \pm 0.2$ & $7.5 \pm 0.4$ & $3.2 \pm 0.4$ & \\
\hline \multicolumn{7}{|l|}{ Abaxial } \\
\hline Amount & $2.6 \pm 0.2$ & $17.3 \pm 1.6$ & $0.4 \pm 0.0$ & $3.2 \pm 0.1$ & $1.6 \pm 0.3$ & \multirow[t]{2}{*}{$25.0 \pm 1.7$} \\
\hline Percent & $10.3 \pm 0.2$ & $69.1 \pm 2.1$ & $1.6 \pm 0.1$ & $12.7 \pm 0.9$ & $6.4 \pm 1.5$ & \\
\hline \multicolumn{7}{|l|}{ Bicolor } \\
\hline \multicolumn{7}{|l|}{ Adaxial } \\
\hline Amount & $1.2 \pm 0.2$ & $17.6 \pm 2.7$ & $0.2 \pm 0.1$ & $1.9 \pm 0.5$ & $1.0 \pm 0.3$ & \multirow[t]{2}{*}{$21.8 \pm 2.8$} \\
\hline Percent & $5.4 \pm 0.7$ & $80.6 \pm 2.3$ & $0.7 \pm 0.4$ & $8.8 \pm 3.1$ & $4.5 \pm 0.7$ & \\
\hline \multicolumn{7}{|l|}{ Abaxial } \\
\hline mount & $1.6 \pm 0.1$ & $17.4 \pm 2.7$ & $0.6 \pm 0.0$ & $3.0 \pm 0.3$ & $1.7 \pm 0.3$ & \multirow[t]{2}{*}{$24.2 \pm 3.4$} \\
\hline Percent & $6.6 \pm 0.8$ & $71.7 \pm 1.2$ & $2.3 \pm 0.2$ & $12.6 \pm 0.8$ & $6.8 \pm 0.3$ & \\
\hline \multicolumn{7}{|c|}{ Mister Lincoln } \\
\hline \multicolumn{7}{|l|}{ Adaxial } \\
\hline Amount & $1.9 \pm 0.5$ & $20.0 \pm 6.3$ & $0.1 \pm 0.0$ & $1.6 \pm 0.8$ & $1.1 \pm 0.4$ & \multirow[t]{2}{*}{$24.8 \pm 7.9$} \\
\hline Percent & $7.8 \pm 0.5$ & $81.0 \pm 1.2$ & $0.2 \pm 0.1$ & $6.5 \pm 1.2$ & $4.5 \pm 0.7$ & \\
\hline \multicolumn{7}{|l|}{ Abaxial } \\
\hline Amount & $1.5 \pm 0.2$ & $16.1 \pm 0.8$ & $0.1 \pm 0.0$ & $2.2 \pm 0.4$ & $1.3 \pm 0.4$ & \multirow[t]{2}{*}{$21.2 \pm 0.8$} \\
\hline Percent & $7.1 \pm 0.6$ & $76.0 \pm 3.1$ & $0.5 \pm 0.1$ & $10.3 \pm 1.9$ & $6.0 \pm 1.7$ & \\
\hline \multicolumn{7}{|c|}{ Garden Party } \\
\hline \multicolumn{7}{|c|}{ Adaxial } \\
\hline Amount & $1.4 \pm 0.3$ & $11.6 \pm 2.9$ & $0.1 \pm 0.0$ & $0.8 \pm 0.2$ & $0.4 \pm 0.1$ & \multirow[t]{3}{*}{$14.3 \pm 3.5$} \\
\hline Percent & $10.0 \pm 0.4$ & $81.1 \pm 1.5$ & $0.3 \pm 0.1$ & $5.8 \pm 0.9$ & $2.8 \pm 0.3$ & \\
\hline \multicolumn{6}{|l|}{ Abaxial } & \\
\hline Amount & $2.0 \pm 0.1$ & $13.9 \pm 1.2$ & $0.2 \pm 0.0$ & $2.4 \pm 0.5$ & $1.2 \pm 0.3$ & \multirow{2}{*}{$19.7 \pm 2.0$} \\
\hline Percent & $9.9 \pm 0.5$ & $70.7 \pm 1.4$ & $1.0 \pm 0.1$ & $12.1 \pm 1.2$ & $6.2 \pm 0.7$ & \\
\hline \multicolumn{7}{|l|}{ Knockout } \\
\hline \multicolumn{7}{|l|}{ Adaxial } \\
\hline Amount & $0.9 \pm \mathrm{ND}$ & $8.8 \pm \mathrm{ND}$ & $0.02 \pm \mathrm{ND}$ & $0.5 \pm \mathrm{ND}$ & $0.4 \pm \mathrm{ND}$ & \multirow[t]{2}{*}{$10.6 \pm \mathrm{ND}$} \\
\hline Percent & $8.7 \pm \mathrm{ND}$ & $83.0 \pm \mathrm{ND}$ & $0.2 \pm \mathrm{ND}$ & $4.5 \pm \mathrm{ND}$ & $3.6 \pm \mathrm{ND}$ & \\
\hline \multicolumn{7}{|l|}{ Abaxial } \\
\hline Amount & $1.1 \pm 0.1$ & $8.9 \pm 1.3$ & $0.1 \pm 0.0$ & $2.4 \pm 0.7$ & $1.4 \pm 0.4$ & \multirow[t]{2}{*}{$13.9 \pm 1.1$} \\
\hline Percent & $8.1 \pm 0.5$ & $63.8 \pm 4.9$ & $0.7 \pm 0.3$ & $17.6 \pm 6.4$ & $9.8 \pm 2.4$ & \\
\hline
\end{tabular}

${ }^{\mathrm{z}} 16-\mathrm{OH} \mathrm{C} \mathrm{C}_{16}$ acid = 16-hydroxy hexadecanoic acid; di-OH $\mathrm{C}_{16}$ acid $=10,16$-dihydroxy hexadecanoic acid; 1,16 dioic acid $=$ hexadecane-1,16-dioic acid; 7-OH dioic acid = 7-hydroxy hexadecane-1,16-dioic acid; $10-\mathrm{OH} \mathrm{C}_{17}$ acid = 10-hydroxy heptadecanoic acid.

y $\mathrm{Two}$ replicates.

$\mathrm{ND}=$ not determined. 
acids were intermediate in abundance, whereas 10-hydroxy heptadecanoic acids and hexadecane 1,16 dioic acids were least abundant in rose leaf cutins. The proportional reduction in the 10,16-dihydroxy hexadecanoic acids and the elevation in the 7-hydroxy hexadecane1,16 dioic acids in abaxial cuticles of 'Knockout' were greatest among the cultivars (Table 1).

Rose leaf wax profiles. Wax samples represented the total extract from both adaxial and abaxial surfaces (not being extracted separately from individual adaxial and abaxial surfaces, like in cutin analysis, as a result of technical constraints). No correlation was evident between the total wax monomer amount and total cutin amount on leaves (Tables 1 and 2). Total leaf cuticular wax amounts were lowest on 'Purple Passion' and 'Knockout', intermediate in 'Mister Lincoln' and 'Garden Party', and highest on 'Bicolor' (Table 2). The major wax constituent on rose leaves was alkanes for all cultivars, varying from $49 \%$ to $67 \%$ of total wax load. The second most abundant wax class was primary alcohols on all but 'Purple Passion' and 'Garden Party', which had slightly higher proportional amounts of esters (Table 2). Free carboxylic fatty acids, aldehydes, and secondary alcohols were least abundant. The major alkane constituent on rose leaves was the 31-carbon homolog, whereas the major primary alcohol was the 26-carbon homolog, in all cultivars (Fig. 1). No large variation in the chain length distribution for any wax class was evident among the five cultivars examined.

Blackspot disease susceptibility rating. Of the five cultivars examined, 'Knockout' exhibited the most resistance to visible blackspot disease with a mean disease susceptibility rating score of 1.0 (with $\approx 10 \%$ of leaves exhibiting blackspot symptoms) (Table 3 ). 'Purple Passion' with a disease rating of 8.8 exhibited the least resistance (with over $80 \%$ of leaves exhibiting disease). 'Bicolor' with a rating of 7.5 was only slightly more resistant than 'Purple Passion', whereas 'Mister Lincoln' with a rating of 1.5 was almost as resistant as 'Knockout'. 'Garden Party' was only moderately resistant, exhibiting blackspot on slightly over half of its leaves. Black- spot disease susceptibility ratings were shown to correlate inversely with wax alkane proportion $\left(\mathrm{R}^{2}=0.63, P=0.05\right)$ and directly with wax ester proportion $\left(\mathrm{R}^{2}=0.81, P=\right.$ 0.05 ), but did not correlate well with other wax parameters, cutin monomer amounts, or any major variations in cutin monomer percentages (linear regression using the LINEST function in Excel [Microsoft Corp., Redmond, WA]).

\section{Discussion}

Cuticle layers over aerial plant surfaces provide the outermost barrier through which most fungal pathogens must enter healthy plants. Even fungi that enter through stomata, like rusts, must penetrate the cuticle membrane lining the substomatal chamber. It is thought that the cuticle provides 1) a physical barrier to the penetration by fungi, 2) chemical signals that inhibit fungal development, or 3) an increase in hydrophobicity of plant surfaces that results in less water retention thereby removing moisture required for spore germination (Jenks and Ashworth, 1999). Theoretically, fungal hyphae may penetrate the cuticle by physically forcing (through turgor pressure) their infection hyphae through contiguous lipidic layers or naturally occurring breaks in the cuticle layer or by degrading and softening the surface lipids by producing cutinases or similar enzymes (Bonnen and Hammerschmidt, 1989; Cruickshank, 1995). Fungal penetration of cuticle layers may also be effected by lipidic components in the cuticle that act as fungal growth regulators.

Epicuticular waxes form the outermost layer over the cuticular membrane and are visible on many plant species as a bluish white-colored coating called glaucousness or bloom. Intracuticular waxes are embedded inside the cutin polyester matrix of the cuticle membrane. The cuticular waxes are primarily long-chain aliphatic waxes of 16 to above 34 carbons in length, except esters, which can be much longer. Like in Rosa 'Charming Parade' and Rosa 'Apollo Parade' (Jenks et al., 2000), we show in five additional cultivars that rose leaf waxes are composed of free fatty acids, aldehydes, alkanes, primary alcohols, and

Table 2. Cuticular wax class by total amount $\left(\mu \mathrm{g} \cdot \mathrm{cm}^{-2} \pm \mathrm{SD}\right)$ and percentage $(\% \pm \mathrm{SD})$ of leaves from the five selected Rosa cultivars.

\begin{tabular}{|c|c|c|c|c|c|c|c|}
\hline & Acids & Aldehydes & $\begin{array}{l}\text { Primary } \\
\text { alcohols }\end{array}$ & Alkanes & $\begin{array}{l}\text { Secondary } \\
\text { alcohols }\end{array}$ & Esters & Totals \\
\hline \multicolumn{8}{|c|}{ Purple Passion } \\
\hline Amount & $0.3 \pm 0.1$ & $0.6 \pm 0.1$ & $2.1 \pm 0.2$ & $5.2 \pm 0.3$ & $0.1 \pm 0.0$ & $2.3 \pm 0.3$ & \multirow[t]{2}{*}{$10.5 \pm 0.4$} \\
\hline Percent & $2.9 \pm 0.5$ & $5.6 \pm 0.5$ & $20.1 \pm 1.6$ & $49.2 \pm 3.3$ & $0.6 \pm 0.5$ & $21.6 \pm 2.5$ & \\
\hline \multicolumn{8}{|l|}{ Bicolor } \\
\hline Amount & $1.2 \pm 0.1$ & $0.7 \pm 0.0$ & $7.4 \pm 0.6$ & $18.6 \pm 2.3$ & $0.9 \pm 0.1$ & $6.6 \pm 0.6$ & \multirow[t]{2}{*}{$35.4 \pm 3.7$} \\
\hline Percent & $3.4 \pm 0.3$ & $1.9 \pm 0.1$ & $21.1 \pm 0.5$ & $52.4 \pm 1.0$ & $2.5 \pm 0.1$ & $18.7 \pm 0.4$ & \\
\hline \multicolumn{8}{|c|}{ Mister Lincoln } \\
\hline Amount & $0.7 \pm 0.1$ & $0.8 \pm 0.0$ & $3.7 \pm 0.3$ & $10.5 \pm 0.6$ & $0.2 \pm 0.0$ & $2.7 \pm 0.5$ & \multirow[t]{2}{*}{$18.6 \pm 1.2$} \\
\hline Percent & $3.9 \pm 0.2$ & $4.5 \pm 0.2$ & $20.1 \pm 0.9$ & $56.3 \pm 1.1$ & $0.9 \pm 0.0$ & $14.3 \pm 1.9$ & \\
\hline \multicolumn{8}{|c|}{ Garden Party } \\
\hline Amount & $1.1 \pm 0.2$ & $2.0 \pm 0.4$ & $1.1 \pm 0.2$ & $12.2 \pm 1.0$ & $1.0 \pm 0.1$ & $2.8 \pm 0.2$ & \multirow[t]{2}{*}{$20.2 \pm 1.7$} \\
\hline Percent & $5.4 \pm 0.8$ & $9.8 \pm 1.4$ & $5.7 \pm 0.7$ & $60.3 \pm 1.9$ & $5.0 \pm 0.4$ & $13.8 \pm 1.3$ & \\
\hline \multicolumn{8}{|l|}{ Knockout } \\
\hline Amount & $0.6 \pm 0.2$ & $0.4 \pm 0.1$ & $2.1 \pm 0.0$ & $10.2 \pm 0.8$ & $0.4 \pm 0.1$ & $1.6 \pm 0.1$ & \multirow[t]{2}{*}{$15.2 \pm 1.0$} \\
\hline Percent & $3.7 \pm 1.5$ & $2.5 \pm 0.7$ & $13.7 \pm 0.8$ & $67.1 \pm 1.9$ & $2.3 \pm 0.3$ & $10.7 \pm 0.3$ & \\
\hline
\end{tabular}

esters with alkanes as the dominant class and the $\mathrm{C}_{31}$ and $\mathrm{C}_{33}$ homologs as the major constituents of the alkane class. Compared with 'Charming Parade' and 'Apollo Parade' that were grown in the greenhouse (Jenks et al., 2000), the leaf ester amounts are much higher on all five outdoor-grown rose cultivars of this study. It is yet unclear to what degree the high esters on outdoor plants are explained by environmental, genotypic, or developmental factors. As for the two previously reported rose cultivars, we likewise show large variation in primary alcohols. Variation in the primary alcohols, however, could not be associated with disease susceptibility. Instead, our results indicate that higher proportions of alkanes are associated with less disease susceptibility in rose, whereas lower proportional amounts of esters are associated with more disease susceptibility. Because only five cultivars were examined; however, these conclusions should be held as tentative until more extensive studies with additional genotypes are performed.

We report here the first analysis of cutin monomers in the Rosa genera. In most plants, cutin monomers are composed primarily of varying amounts of 16 and 18 carbon length hydroxy fatty acids (Xiao et al., 2004). Rose is unique in that its cutin is composed mostly of 16 carbon hydroxy acids with only trace or very low amounts of 17 and 18 carbon acids (not shown). As a comparison with rose, minor amounts of the more rare odd chain 15 and 17 carbon cutin monomers, many with hydroxyl groups, have been reported in other plant species (Holloway et al., 1972; Kurdyukov et al., 2006). When averaged across the five cultivars, rose leaf cutin consists of roughly $75 \%$ of 10,16 -dihydroxy hexadecanoic acids, $10 \%$ of 7-hydroxy hexadecane-1,16-dioic acids, $8 \%$ of 16-hydroxy hexadecanoic acids, 5\% of 10-hydroxy heptadecanoic acids, and 1\% hexadecane-1,16dioic acids. The amount of individual cutin monomers did not vary greatly between cultivars, except in a few cases. Notably, the percentage of the 10,16-dihydroxy hexadecanoic acid was slightly higher on adaxial than abaxial surfaces. Whether these chemical differences, however, have important physiological functions such as in plant disease resistance or are simply an effect of growth in different environmental conditions (i.e., adaxial surfaces typically receive more direct light than abaxial) is unknown. Also, the abaxial surface of 'Knockout', the most disease-resistant cultivar, had especially low proportions of the 10,16-dihydroxy hexadecanoic acids and elevated 7-hydroxy hexadecane 1,16-dioic acids when compared with the adaxial surface of 'Knockout'. Although many pathogens infect abaxial surfaces primarily, like downy mildews, the blackspot pathogen surveyed here, however, is thought to infect both leaf surfaces. Further studies are needed to determine whether differences in the cutin monomer profiles of adaxial and abaxial surfaces of rose leaves are mechanistically important in the infection processes used by the blackspot pathogen. 

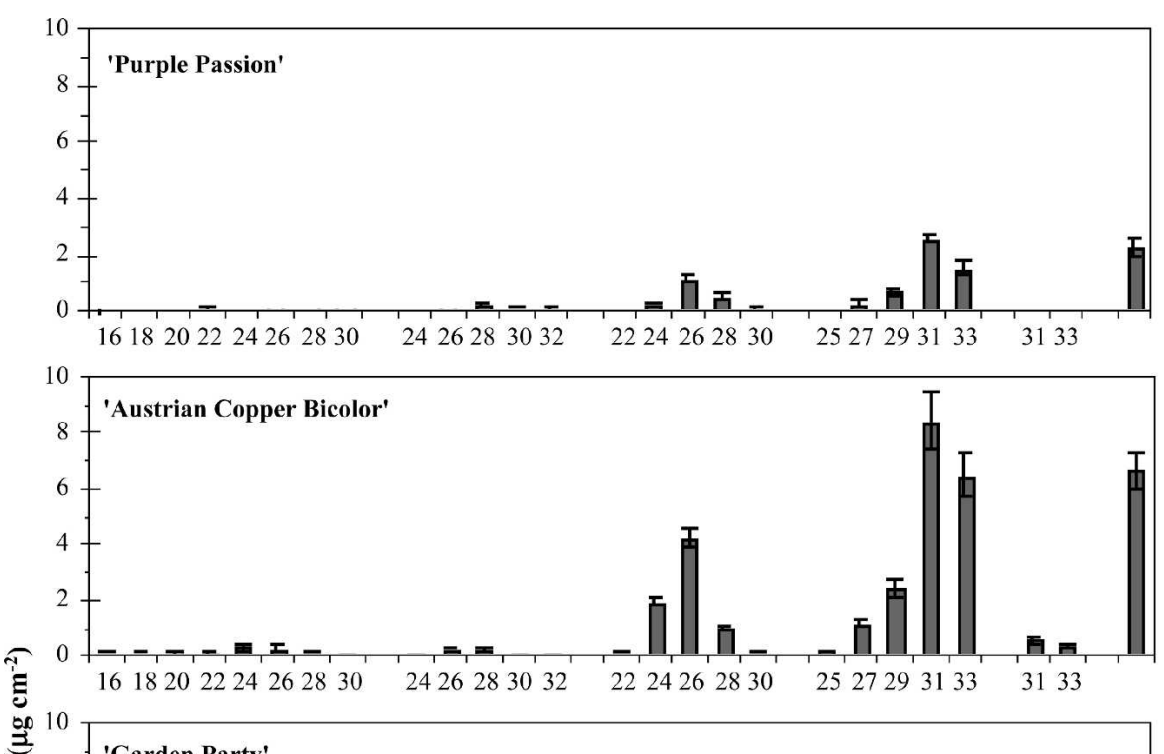

'Garden Party'
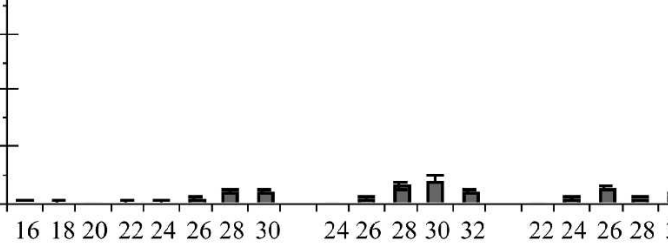

10 'Mr.Lincoln'

8

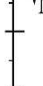

6

$4-$

2

0

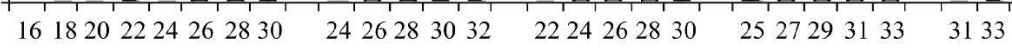

10

'Knockout'

8

6

4

2

1.

16182022 acids
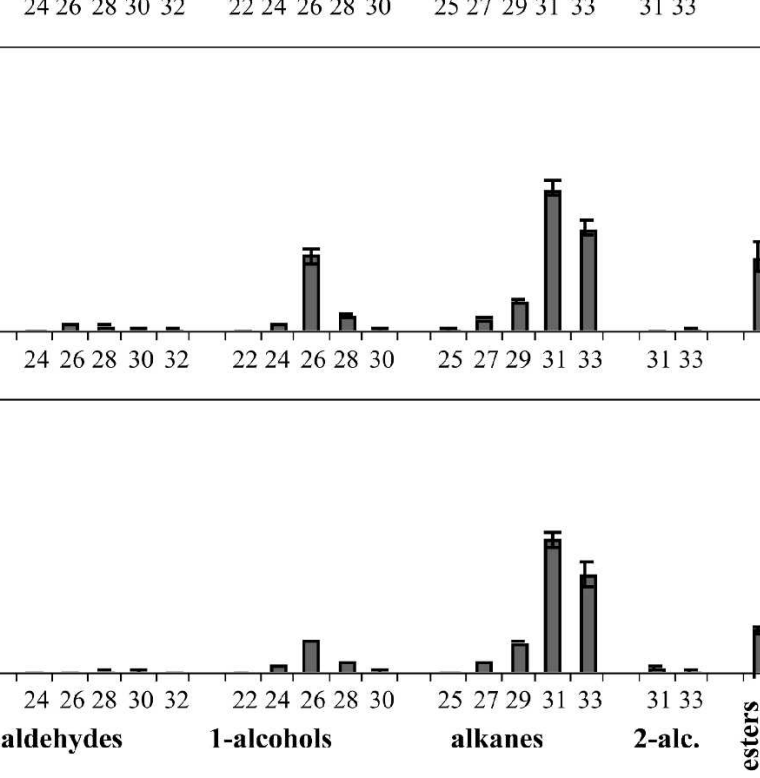

Fig. 1. Individual wax constituent amounts per leaf area $\left(\mu \mathrm{g} \cdot \mathrm{cm}^{-2} \pm \mathrm{sD}\right)$ for all five Rosa genotypes. The carbon chain lengths are labeled on the horizontal axis. 1-alcohols, primary alcohols; 31 carbon 2-alc., hentriacontan-12-ol, hentriacontan-11-ol, hentriacontan-10-ol; 33 carbon 2-alc., tritriacontan-12-ol, tritriacontan-13-ol, tritriacontan-11-ol, tritriacontan-14-ol. The secondary alcohol isomers in the preceding list are in order of decreasing proportions.

\section{Conclusions}

Lipids of the plant cuticle are known to function in plant-pathogen interactions. To date, however, a clear understanding of cuticular mechanisms that might provide plant resistance to pathogens is still lacking. In the present study, we demonstrate that large variations in cuticle lipid profiles exist among five rose cultivars with cutin amounts varying more than twofold and wax amounts varying more than threefold. The cutin mono- mer 10,16-dihydroxy hexadecanoic acid was the most abundant cutin monomer on rose leaves and was slightly more abundant on adaxial than abaxial leaf surfaces. Alkanes dominated the wax profiles of rose leaves with primary alcohols and esters also being found in abundance. We report a large amount of variation in these cuticle lipid profiles of rose, and associations between rose disease resistance and leaf wax alkane and ester profiles. Further studies to determine the degree to which these cuticle properties are
Table 3. Visual disease susceptibility ratings for blackspot symptoms incited by the pathogen Diplocarpon rosae on selected rose cultivars with zero assigned to cultivars exhibiting no blackspot disease and 10 assigned to cultivars with $100 \%$ of leaves exhibiting disease.

\begin{tabular}{lc}
\hline Cultivar & Visual rating \\
\hline Purple Passion & $8.8 \pm 0.6$ \\
Bicolor & $7.5 \pm 0.5$ \\
Mister Lincoln & $1.5 \pm 0.6$ \\
Garden Party & $5.4 \pm 0.6$ \\
Knockout & $1.0 \pm 0.2$ \\
\hline
\end{tabular}

important in rose interactions with diseasecausing pathogens like those that cause blackspot are warranted.

\section{Literature Cited}

Bonnen, A.M. and R. Hammerschmidt. 1989. Role of cutinolytic enzymes in infection of cucumber by Colletrichum lagennarium. Physiol. Mol. Plant Pathol. 35:475-481.

Braun, U. and S. Takamatsu. 2000. Phylogeny of Erysiphe, Microsphaera, Uncinula (Erysipheae) and Cystotheca, Podosphaera, Sphaerotheca (Cystotheceae) inferred from rDNA ITS sequences-Some taxonomic consequences. Schlechtendalia 4:1-33.

Carlson-Nilsson, B.U. and C.G. Davidson. 2006. Variation in resistance to Marssonina rosae (Lib.) Died. among different Rosa L. cultivars and species including three dogrose species (Rosa sect. Caninae). Sci. Hort. 109:353-360.

Castledine, P., B.W.W. Grout, and A.V. Roberts. 1981. Cuticular resistance to Diplocarpon rosae. Trans. Br. Mycology Society 77:665666.

Cruickshank, R.H. 1995. The influences of epicuticular wax disruption and cutinase resistance on penetration of tomatoes by Colletotrichum gloeosporioides. J. Phytopathol. 143:519-524.

Eglinton, G. and D.H. Hunneman. 1968. Gas chromatographic-mass spectrometric studies of long chain hydroxy acids-I. Phytochemistry 7:313-322.

Genders, R. 1965. The rose. A complete handbook. Bobbs-Merrill Co., Indianapolis, IN. p. 62.

Holcomb, G.E. and T.J. Raiford. 2001. Reaction of rose cultivars to black spot disease, 2000. Biological and cultural tests for control of plant diseases. 21, Report number 16:052.

Holloway, P.J. 1982. The chemical constitution of plant cutins, p. 45-85. In: Cutler, D. Alvin, K. Price (eds.). The plant cuticle. Linnean Society Symposium Series. Academic Press, London, UK.

Holloway, P.J. 1984. Cutins and suberins, the polymeric plant lipids, p. 321-345. In: H.K Mangold, G. Zweig, and J. Sherma (eds.). CRC handbook of chromatography: Lipids. Vol I. CRC Press, Boca Raton, FL.

Holloway, P.J., A.H.B. Deas, and A.M. Kabaara. 1972. Composition of cutin from coffee leaves. Phytochemistry 11:1443-1447.

Hong, C.X., T. Banko, M. Stefani, G. Epelman, and J. Overton. 2001. Evaluation of rose resistance to black spot and powdery mildew, 2000. Biological and cultural tests for control of plant diseases. 21, Report number 16:053.

Jenks, M.A., L. Anderson, R. Teusink, and M. Williams. 2000. Leaf epicuticular waxes of Rosa Apollo Parade ${ }^{\circledR}$ and Rosa Charming Parade $^{\circledR}$ as effected by plant development, drought, and paclobutrazol treatments. Physiol. Plant. 112:62-70.

HortScience Vol. 42(7) December 2007 
Jenks, M.A. and E.N. Ashworth. 1999. Plant epicuticular waxes: Function, production, and genetics, p. 1-68. In: J. Janick (ed.). Horticultural reviews. Vol. 23. John Wiley \& Sons, Inc., New York.

Jenks, M.A., S.D. Eigenbrode, H.A. Tuttle, and K.A. Feldmann. 1995. Leaf epicuticular waxes on the eceriferum mutants of Arabidopsis. Plant Physiol. 108:369-377.

Jenks, M.A., R.A. Joly, P.J. Rich, P.J. Peters, J.D. Axtell, and E.N. Ashworth. 1994. Chemically-induced cuticle mutation affecting epidermal conductance to water vapor and disease susceptibility in Sorghum bicolor (L.) Moench. Plant Physiol. 105:12391245.

Jenks, M.A., H.A. Tuttle, S.D. Eigenbrode, and K.A. Feldmann. 1995. Leaf epicuticular waxes of the eceriferum mutants in Arabidopsis. Plant Physiol. 108:369-377.
Kurdyukov, S., A. Faust, S. Trenkamp, S. Bär, R. Franke, N. Efremova, K. Tietjen, L. Schreiber, H. Saedler, and A. Yephremov. 2006. Genetic and biochemical evidence for involvement of HOTHEAD in the biosynthesis of long-chain $\propto-, \omega$-dicarboxylic fatty acids and formation of extracellular matrix. Planta 224:315-329.

Larson, R.A. 1992. Introduction to floriculture. Academic Press, Inc., New York, p. 69-92.

Palmer, J.G., P. Semeniuk, and R.N. Stewart. 1966. Roses and blackspot. I. Pathogenicity to excised leaflets of Diplocarpon rosae from seven geographic locations. Phytopathology 56:1277-1282.

Reddy, S., J.A. Spencer, and S.E. Newman. 1992. Leaflet surfaces of blackspot-resistant and susceptible roses and their reactions to fungal invasion. HortScience 27:133-135.

Riederer, M. and J. Schönherr. 1986. Quantitative gas chromatographic analysis of methyl esters of hydroxy fatty acids derived from plant cutin. J. Chromatogr. 360:151-161.

von Malek, B. and T. Debner. 1998. Genetic analysis of resistance to blackspot (Diplocarpon rosae) in tetraploid roses. Theor. Appl. Genet. 96:228-231.

Xiao, F., S.M. Goodwin, Y. Xiao, Z. Sun, D. Baker, X. Tang, M.A. Jenks, and J.M. Zhou. 2004. Arabidopsis CYP86A2 negatively regulates Pseudomonas syringae type III genes and is required for cuticle development. EMBO J. 23:2903-2913.

Xue, A.G. and C.G. Davidson. 1998. Components of partial resistance to black spot disease (Diplocarpon rosae Wolf) in garden roses. HortScience 33:96-99.

Yokoya, K., K.I. Kandasamy, and S. Walker. 2000. Resistance of roses to pathotypes of Diplocarpon rosae. Ann. Appl. Biol. 136:1520 . 